\title{
Is Compensation Enough? Relational Concerns in Responding to Unintended Inequity
}

\author{
Tyler G. Okimoto \\ New York University \\ Tom R. Tyler \\ New York University
}

\begin{abstract}
Traditional justice models suggest that monetary compensation is an adequate response to unintended distributive harm. This perspective is widely accepted in real world settings, and is manifested in policies ranging from worker compensation to the court-based tort system. Drawing on the arguments from relational models of authority, we hypothesize that compensation for losses may be viewed by victims as an inadequate response to the situation, even when those losses are accidental and not the result of intentional harm. In four experimental studies, respondents were asked to react to the receipt of monetary compensation for accidental distributive inequities under varying degrees of relational concern. Results indicate that judgments about the favorability of compensation are only one aspect of people's reaction to responses to harm. In each case, victims displayed more favorable reactions toward the group when compensation was supplemented by relational concern.
\end{abstract}

KEYWORDS accidental, compensation, distributive injustice, relational concern

Discussions about how to respond to unintended harms are often associated with the use of equity principles, by which people try to 'even the score' in response to an injustice (Austin, Walster, \& Utne, 1976; Brickman, 1977). This literature suggests that, when harm is unintended or accidental, compensation is viewed as an appropriate response to that harm. Compensation 'restores' justice through provision of money meant to compensate for lost income or to pay for necessary medical treatment. This equity based approach to accidental harm is widely represented in organizations and society, in systems such as workers' compensation and tort based remedies which seek to quantify accidental losses and provide victims with compensation for the cost associated with the accident.

\section{Author's note}

Address correspondence to Tyler G. Okimoto, School of Psychology, Flinders University, GPO Box 2100, Adelaide SA 5001, Australia [email: tyler.okimoto@flinders.edu.au]. 
In the case of unintentional harm, researchers have argued that people's reactions are shaped by their evaluations of the favorability of the resources provided in compensation for the harm (Darley \& Pittman, 2003). While compensation, as it has been argued, is an adequate response to accidental harm, such harm has often been distinguished from intentional harm, where the injustice is the result of intentional actions (Darley \& Pittman, 2003). Research has shown that with intentional harm people do not view compensation alone as an adequate or suitable response (Hogan \& Emler, 1981; Horai, 1977; Tyler, Boeckmann, Smith, \& Huo, 1997). Judgments about the appropriate restorative response to an injustice are not only shaped by instrumental judgments about appropriate compensation, but also by the victim's concerns about the relational implications of harm for their status within groups and organizations (Tyler \& Blader, 2003; Tyler \& Lind, 1992). This argument flows from the relational model of authority (Tyler \& Lind, 1992), and is illustrated in research on the nature of justice motivations (see Tyler et al., 1997, for review).

It has been suggested that when a transgressor intentionally violates the rules or morals set by society, a symbolic statement is made regarding the relationship between the offender and the victim, or the offender's respect for the rules of society (Tyler et al., 1997). When an offender purposefully violates norms regarding distributive fairness, monetary rewards are not adequate as a response, since the procedural violation of intentionality also demands some type of symbolic restoration as well (Brown \& Harris, 1989; Tyler et al., 1997). The prior literature suggests that there is a need for distributive and procedural restoration (addressing instrumental and relational concerns) when both have been violated, such as when distributive inequity is intentional, while compensation alone is an adequate response to unintentional harms (Darley \& Pittman, 2003).

But how fundamental are these relational issues? Are people concerned with relational issues even in the case of accidental distributive harm, when the injustice does not communicate symbolic meaning regarding the value of the injustice victim? We hypothesize that relational issues are raised by distributive injustices, irrespective of whether or not the injustice is accidental or unintended. Hence, we expect that the adequate restoration of these accidental inequities will also involve addressing the relational concerns of the victim, in addition to the restoration of equity. Concern for these relational issues is not only important for general positive reactions toward the group, but also the organizational and group-level implications that have been shown to be associated with perceptions of fair procedures.

While monetary compensation may be the most effective means of restoring equity, the procedures by which that compensation occurs are also very important, and unfair procedures ubiquitous in the execution or implementation of the compensatory act may undermine the benefit of the distributive restoration. If the compensation process employs procedures that are lacking in relational concern, thereby implying a lack of concern by the group, the positive victim-group relationship may be diminished, even if adequate restitution is proffered. For example, settlements aimed at avoiding organizational or societal penalties, or other instrumental motivations on the part of the compensating party, may communicate a lack of concern for the victim. Conversely, if compensation is accompanied by procedural elements that address relational concerns, such as an apology, it will be more satisfactory and protect the victim-group relationship from being threatened by the injustice.

From the victim's point of view, fair procedures which exhibit relational concern, reaffirming membership status and value, can take many forms as long as the perceived relative status of the parties is restored (or reaffirmed) through some type of restitution or punishment that has symbolic value (Kahan, 1996; Karp, 1998) proportional to the procedural injustice (Carlsmith, Darley, \& Robinson, 2002; Walster, Walster, \& Berscheid, 1978), and in addition to the restoration of equity. For example, apologies that are perceived as sincere (Blackman \& Stubbs, 2001; Pepitone, 1975) may function as a restorative gesture for procedural injustices because they 
imply that the transgressors are remorseful of the actions that they have taken, thereby symbolically subordinating their own status in the relationship (Heider, 1958; Rumsey, 1976; Wood \& Mitchell, 1981), and showing that they recognize the consequence of their actions and will not repeat the offense (Gold \& Weiner, 2000; Schwartz, Kane, Joseph, \& Tedeschi, 1978).

If, however, the subsequent responses of group representatives following an accidental distributive injustice are not perceived to exhibit relational concern for the victim and his or her needs, the resolution will not be viewed as satisfactory to the victim. Failure to reaffirm the victim's perceived status as a valued member of the group during the compensation process may lead to decreased identification and poor victim-group relations.

In other words, compensation must be awarded in relationally sensitive ways, since victims are sensitive both to whether the provision of compensation itself is adequate as well as the interpersonal message communicated by the manner in which they are compensated. This is the case in both intentional and accidental distributive injustices, contrary to expectations from past research which view only intentional injustices as requiring relational concern (Darley \& Pittman, 2003). By compensating a victim in a way that communicates a lack of concern for the victim or denial of recognition or responsibility on the part of the transgressor, the relational needs of the victim are not taken into account. Even if the victim is compensated for the injustice, while satisfied with the distributive fairness of their compensation, he or she may still feel disrespected and undervalued as a member of the group in which the injustice occurred.

As such, the provision of compensation alone for an accidental injury, even when it is viewed as favorable, will not be an adequate response to the harm. The victim may question the value of his or her membership status even when the distributive injustice was accidental, thereby raising concern for relational cues or evoking interest in relational verification in addition to the concern for equity. Therefore, when an accidental distributive injustice is compensated through distributive means, people will perceive the compensatory act as more procedurally fair when the group provides compensation through a procedure that also addresses relational concerns (by acknowledging that a mistake has been made and expressing remorse), even though the monetary award is objectively identical.

Hypothesis 1: When attempting to restore justice following an accidental inequity, perceptions of procedural fairness will be higher if the equitable compensation is presented with additional relational concern, compared to when the equitable compensation is presented without relational concern.

This pattern of results would indicate that, while the type and amount of compensation received as dictated by taking an equity framework alone may be adequate to satisfy the need for outcome restoration, procedural fairness may vary independently of the actual monetary award.

The distinction between the fairness of the outcomes and the fairness of the procedures is an important one to make in this context. In distributive matters, the applicability and favorability of the compensation itself may be the focus of decision-makers' evaluations of the proposed resolution. However, if relational concerns are heightened by the experience of an injustice, procedural fairness inherent in the compensation process may have an unexpected impact on the group as a whole.

As past research has shown (Tyler \& Lind, 1992), members of groups use procedural justice information to infer their value within the group, and any detriment in procedural fairness may indicate to the victim that he or she is not a valued group member. As much research has shown, unfair procedures may have negative consequences for the group, including lower commitment (Tyler \& Blader, 2003), lower evaluations and attitudes toward the group (Konovsky \& Cropanzano, 1991; Tyler, 1990), and higher rates of turnover (Jones \& Skarlicki, 2003) or other withdrawal behaviors (Dailey \& Kirk, 1992; Huo, Smith, Tyler, \& Lind, 1996). As a result, even though satisfaction with the outcomes received in a compensatory act may suffice in appeasing the victim's desire for distributive retribution, the group is still at risk of 
jeopardizing the individual-group relationship. More specifically:

Hypothesis 2: When attempting to restore justice following an accidental inequity, reactions towards the group as a whole will be more favorable if the equitable compensation is presented with additional relational concern, compared to when the equitable compensation is presented without relational concern.

To further argue the idea that these reactions are not driven by outcome favorability alone but rather by the impact that relational concern has on perceived membership value, we expect additional analyses to provide support for mediation. In particular, we believe that additional provision of relational concern should result in differing levels of group evaluations because of its impact on perceived membership value and status.

These hypotheses are conceptually distinct from those of previous compensation discussions. Instead of focusing on the compensatory or apologetic actions of the transgressor as they relate to attributions of responsibility and sincerity judgments (Schwartz et al., 1978; Shaw, Wild, \& Colquitt, 2003), this line of research focuses on the broader impact of responses to injustice, independent of perceptions of intent. In the situations we examine, there is no question of intentionality, all involving accidental mistakes that indirectly resulted in material losses. These unintentional transgressions have not been discussed as requiring specific concern for relational maintenance (Darley \& Pittman, 2003), particularly in instances where the provision of compensation has already addressed equity concerns.

Taken together these hypotheses argue that, while compensation for accidental harm may restore feelings of outcome fairness, compensation alone is an inadequate response to accidental harm. Even unintentional harms have relational implications that should be addressed by showing relational concern (through fair and supportive compensation procedures). Groups and organizations need to maintain a broader framework that addresses these relational issues, even in purely distributive matters, since commitment to the group following efforts to deal with even accidental harms are linked to relational as well as instrumental justice concerns.

\section{Study 1}

Study 1 consists of two similar studies that lay the groundwork support for our hypotheses regarding reactions to the group following varying degrees of relational concern accompanying compensation. While both are similar in design, Study 1B provides additional measures and mediational analysis supporting our proposed arguments.

\section{Method}

Participants Forty-four undergraduate students (39\% male) recruited from an introductory psychology course participated in the study. Participants received partial credit towards the fulfillment of course requirements in exchange for their participation, and had an average age of 19.4 years. The scenarios in this study concerned university-operated student housing, in order to maximize participant involvement. Therefore demographics were also collected regarding each participant's experience living in student housing; $84 \%$ of the participants had lived in student housing for an average time period of 3.15 semesters, and $85 \%$ of those with direct student housing experiences were currently living in student housing. Two participants reported having been employed by student housing, and those participants were removed from all analyses due to their potential familiarity with actual housing policies.

Procedure The participants in the study were informed that the research investigated student opinions on university policies and procedures. They were told that they would be looking at letters of complaint that had been sent by residents of university housing, filing formal grievances against the housing administration. Following each complaint, participants received a written response from the housing administration stating the actions that would be taken to resolve the conflict. Participants were instructed 
to imagine themselves as the student in each situation, and respond to questions as if they were that student.

Each of the complaints provided to subjects involved an unintentional mistake that a housing employee had made, which cost each of the three housing residents a monetary loss of approximately US $\$ 200$. One of the scenarios involved a housing payment that was not processed in an appropriate amount of time, resulting in a late registration fee. The second scenario concerned a late checkout fee incurred by the student, due to misinformation provided by a housing employee. A third case involved an unfounded utilities charge that a student was compelled to pay in order to register on time, even though the charge was due to a clerical error made by housing staff. Each of these cases dealt specifically with an unintentional mistake made by housing staff involving the same amount of monetary loss, and the order of presentation was varied across subjects, as was the relational concern manipulation paired with each scenario.

Experimental manipulations In Study 1A, each subject received all three conditions of the relational concern manipulation, allowing for a three-level within-subjects design. These levels included two conditions that satisfied equity concerns alone (no relational concern), presenting fair compensation as a settlement or a compulsory payment, and a third level in which a group representative acknowledged the mistake and expressed remorse, thereby attempting to address relational concerns in addition to the equity restoration. Study 1B, however, only included two within-subject justification conditions, presenting fair compensation as a settlement (equity concern alone) or as an acknowledgment (equity and relational concern).

The provision of relational concern was manipulated by presenting the $\$ 200$ monetary compensation as a settlement given in order to appease the student while preventing the need for further judiciary action (equitably fair), a compulsory payment that the housing administration was forced to make by a higher authority regardless of their position (equitably fair), or as an acknowledgment of responsibility (equitably fair and relationally sensitive). These manipulations were given in the context of a form letter from student housing, and included one of three statements:

Compensation only: Settlement - 'We have come to this decision because we have been informed that you are interested in pursuing the complaint with the judiciary committee and have requested a formal hearing. Our policy concerning small claims dictates that we compensate you $\$ 200$, due to the cost and time involved in participating in a formal judiciary hearing'.

Compensation only: Compulsory payment (Study 1A only) - 'We have arrived at this decision because the Coordinator for Residential Student Services received a copy of your complaint, and has directed us to compensate you $\$ 200$. This decision has been made as a matter of policy, even though we have not reviewed your grievance and therefore have no position on the merits of your claim'.

Compensation and relational concern - 'We have come to this decision because we realize that our staff may have made mistakes, and we wish to compensate you as much as is reasonably possible'.

While the compensation only conditions (settlement and compulsory payment) restore equity by providing a monetary award, they do not show any relational concern for the victim.

The letters from the housing office were addressed to the student in the corresponding scenario, and concluded with a statement expressing hope that the resolution solved the issue in question.

Dependent measures Checks were collected, assessing outcome favorability $(\alpha=.68)$ and overall fairness of the resolution $(\alpha=.74)$. Multiple scales were also constructed assessing various aspects of participants' reactions to each scenario. A composite measure of procedural fairness $(\alpha=.95)$ was assessed. Each questionnaire also assessed a number of related measures evaluating student housing at the university in general, and student relations with university housing as a whole. These measures included items assessing an affective evaluation of university housing, satisfaction with university housing, intent to stay in housing, and identification with the 
housing community. Reactions to these items should be similar as they all indicate global reactions regarding participants' relationship with the group. For parsimony, these items were combined into a single scale $(\alpha=.94)$ assessing reactions towards the group. When analyzed in four separate scales, the pattern of results was identical. This is not meant to imply that all items are not conceptually distinct, only that in this particular analysis examining each scale independently did not provide additional information. Higher scale ratings indicated more favorable evaluations. All items were assessed on 7-point scales, and were adapted from items used in previous justice research (Tyler \& Lind, 1992). Actual scale items can be found in Appendix A.

Study 1B included additional measures of interest. As with Study 1A, manipulation checks of outcome favorability $(\alpha=.68)$ and resolution fairness $(\alpha=.65)$ were assessed, as well as composite measures of procedural fairness $(\alpha=.91)$, and reactions towards the group $(\alpha=.92)$. In order to assess the participant's perceived value and status level in the group, 'group standing' measures were included, classified into three categories: perceived membership value in the group $(\alpha=.98)$, perceived value compared to housing staff $(\alpha=.97)$, and perceived status in the group hierarchy (1 item). Actual items for the perceived value and relative value measures can be found in Appendix A. The status measure consisted of a single item asking, 'In the housing hierarchy, at what level does university housing view you?', and the request to rate their opinion of 'very low-very high'. One final measure assessed the participant's willingness to accept the resolution offered by the university housing administration. This measure consisted of a single item asking, 'How willing would you be to voluntarily accept the decision made by university housing?'

It should also be noted that, although not specifically discussed, participants also reported pre-resolution outcome favorability and procedural fairness ratings (fairness of the scenario presented) in order to verify that participants interpreted the scenario as we have suggested. All studies showed consistently low ratings of outcome favorability, and consistently high ratings of procedural fairness, corroborating the notion that the scenarios of accidental distributive harm were not also perceived as procedurally unjust.

\section{Results}

Study 1A Means and standard deviations for Studies $1 \mathrm{~A}$ and $1 \mathrm{~B}$, as well as indications of significant paired comparisons within each scale, can be found in Table 1 . In order to verify the consistency of outcome favorability in the scenarios, an analysis of variance was conducted, revealing that there were no significant differences between perceptions of outcome favorability $(F(2,38)=0.99, n s)$, regardless of whether the compensation given was presented as an equity restoration alone (compulsory payment or settlement), or an equity restoration with the additional attempt to show relational concern. Outcome favorability ratings were consistently high. Unexpectedly however, perceptions of fairness of the resolution did reveal a significant effect of relational concern $\left(F(2,38)=4.50, p<.05, \eta^{2}=.192\right)$, with showing relational concern in addition to the equity restoration yielding the highest perceptions of fairness. Paired comparisons were then conducted to specify the parameters of the effect, showing that the relational concern condition was rated as significantly more fair than the settlement condition $(t(19)=2.80, p<.05)$. Although not significant, a trend was also apparent where the relational concern condition was viewed as more fair than the compulsory payment condition $(t(19)=1.84, p=.08)$. The compulsory and settlement conditions were not significantly different from each other.

Analysis of variance was conducted on procedural fairness perceptions, revealing a significant effect for relational concern $(F(2,38)=$ $\left.15.60, p<.001, \eta^{2}=.451\right)$, with the relational concern condition providing the most fair process. Additional paired comparisons were done on the procedural fairness scale, revealing that the relational concern condition was perceived as significantly more procedurally fair to subjects than both the compulsory condition $(t(19)=3.77$, $p<.005)$, and the settlement condition $(t(19)=$ $5.35, p<.001)$. The compulsory and settlement 
Table 1. Study 1: Means and standard deviations for dependent measure scales by condition

\begin{tabular}{|c|c|c|c|}
\hline & $\begin{array}{l}\text { Compensation only: } \\
\text { (settlement) }\end{array}$ & $\begin{array}{l}\text { Compensation only: } \\
\text { (compulsory payment) }\end{array}$ & $\begin{array}{c}\text { Compensation \& } \\
\text { relational concern } \\
\text { [Study } 1 \text { A only] }\end{array}$ \\
\hline \multicolumn{4}{|l|}{ Outcome favorability } \\
\hline Study 1A: & $5.37(1.13)_{\mathrm{a}}$ & \multirow[t]{2}{*}{$5.55(0.86)_{\mathrm{a}}$} & $5.80(0.96)_{\mathrm{a}}$ \\
\hline Study $1 B:$ & $5.39(1.04)_{\mathrm{a}}$ & & $5.95(0.74)_{a}$ \\
\hline \multicolumn{4}{|l|}{ Fairness of resolution } \\
\hline Study 1A: & $4.68(1.43)_{\mathrm{a}}$ & \multirow[t]{2}{*}{$5.08(1.00)_{\mathrm{ab}}$} & $5.68(0.89)_{\mathrm{b}}$ \\
\hline Study $1 B:$ & $4.73(0.98)_{\mathrm{a}}$ & & $5.45(0.60)_{\mathrm{b}}$ \\
\hline \multicolumn{4}{|l|}{ Procedural fairness } \\
\hline Study 1A: & $3.75(1.67)_{\mathrm{a}}$ & \multirow[t]{2}{*}{$4.15(1.56)_{\mathrm{a}}$} & $5.96(1.25)_{\mathrm{b}}$ \\
\hline Study 1B: & $4.11(1.47)_{\mathrm{a}}$ & & $5.79(0.64)_{\mathrm{b}}$ \\
\hline \multicolumn{4}{|l|}{ Reactions towards the group } \\
\hline Study 1A: & $3.01(1.18)_{\mathrm{a}}$ & \multirow[t]{6}{*}{$3.25(1.16)_{\mathrm{a}}$} & $4.12(1.08)_{\mathrm{b}}$ \\
\hline Study $1 B:$ & $3.41(1.11)_{\mathrm{a}}$ & & $4.14(0.97)_{\mathrm{b}}$ \\
\hline Membership value ( $1 B$ only) & $3.17(1.63)_{\mathrm{a}}$ & & $4.61(1.44)_{\mathrm{b}}$ \\
\hline Relative value (1B only) & $2.90(1.30)_{\mathrm{a}}$ & & $3.72(1.14)_{\mathrm{b}}$ \\
\hline Perceived hierarchy ( $1 B$ only) & $2.73(1.45)_{\mathrm{a}}$ & & $3.91(1.41)_{\mathrm{b}}$ \\
\hline Willingness to accept ( $1 B$ only) & $5.36(1.62)_{\mathrm{a}}$ & & $6.32(0.84)_{\mathrm{b}}$ \\
\hline
\end{tabular}

Notes: Standard deviations appear in parentheses. All ratings were done on 7-point scales, and the higher the number, the higher the level of favorability, fairness, etc. $N=20$ in Study 1 A and $N=22$ in Study 1 B.

Means within rows that do not share subscripts differ significantly at $p<.05$, as indicated by paired $t$ tests for comparisons between relational concern conditions (settlement, compulsory payment, or acknowledgment) for each scale.

conditions, however, were not significantly different.

In regard to subjects' global reactions towards the group, analysis of variance revealed a significant effect for relational concern $(F(2,38)=6.69$, $\left.p<.005, \eta^{2}=.260\right)$, with subjects reporting more favorable reactions in the relational concern condition. Paired $t$ tests showed a significant difference between the relational concern and compulsory conditions $(t(19)=2.39, p<.05)$, and a significant difference between relational concern and settlement conditions $(t(19)=3.15$, $p<.005)$. No significant difference was found between the compulsory and settlement conditions.

Study 1B An analysis of variance concluded that there were no significant differences in perceptions of outcome favorability across relational concern conditions $(F(1,21)=4.18$, $p=.054)$, however a trend was apparent. Ratings of overall fairness revealed a significant effect $\left(F(1,21) 7.60, p<.05, \eta^{2}=.266\right)$, with higher fairness ratings given in the relational concern condition.

The measure of procedural fairness revealed a significant effect for relational concern $(F(1,21)=$ 19.32, $\left.p<.001, \eta^{2}=.479\right)$, with compensation presented with relational concern yielding higher perceptions of procedural fairness compared to the condition in which compensation was presented without relational concern.

For the measure of change in perceived value in the group, there was a significant difference between the two relational concern conditions $\left(F(1,21)=11.66, p<.005, \eta^{2}=.357\right)$, such that individual ratings of perceived group value were higher when the compensation was presented with relational concern, compared to when the compensation was presented with equity concern alone. For perceptions of value relative to university staff, again a significant difference 
between conditions was revealed $(F(1,21)=12.06$, $p<.005, \eta^{2}=.365$ ), with the relational concern condition yielding higher ratings. The single item assessing perceived status in the group hierarchy also revealed significant differences for relational concern conditions, $(F(1,21)=13.10$, $\left.p<.005, \eta^{2}=.384\right)$, showing higher perceived status when the compensation was presented with relational concern.

An analysis of variance was also conducted on participant reactions towards the group. There was a significant main effect for relational concern $\left(F(1,21)=12.78, p<.005\left(\eta^{2}=.378\right)\right.$. When compensation was presented with additional relational concern, it yielded higher group evaluations than when the equitable compensation was presented alone, without relational concern.

Lastly, on the single item assessing participant's willingness to voluntarily accept the resolution presented by the university housing administration, there was also a significant difference for relational concern $(F(1,21)=8.26$, $\left.p<.01, \eta^{2}=.282\right)$. When the compensation awarded in the resolution was presented with relational concern, participants were more willing to voluntarily accept that resolution, compared to when the group simply presented the equitable compensation.
Mediation analysis To test the mediating effects hypothesized in this study, we employed the methods suggested by Baron and Kenny (1986), using hierarchical regression methods to demonstrate the reduction in strength of the direct associations after entering the mediating variables, and tested the significance of both the direct and indirect paths (see Figure 1). The simple effect of relational concern on reactions towards the group was significant $(\beta=.35, t=2.42, p<.05)$. However, when controlling for perceived membership value, this direct effect becomes insignificant $(\beta=.12$, $t=0.85, p=.40$ ), while the effect of membership value on reactions towards the group is significant $(\beta=.55, t=3.97, p<.001)$.

\section{Discussion}

As predicted, perceptions of procedural fairness were higher when the monetary compensation was presented with additional concern for relational issues (acknowledging responsibility and expressing remorse) compared to instances when the same compensation was presented without relational concern. This was true irrespective of the fact that the outcomes provided were objectively identical, with participants evaluating the outcomes in all conditions as being equally favorable. Hence, the concerns that

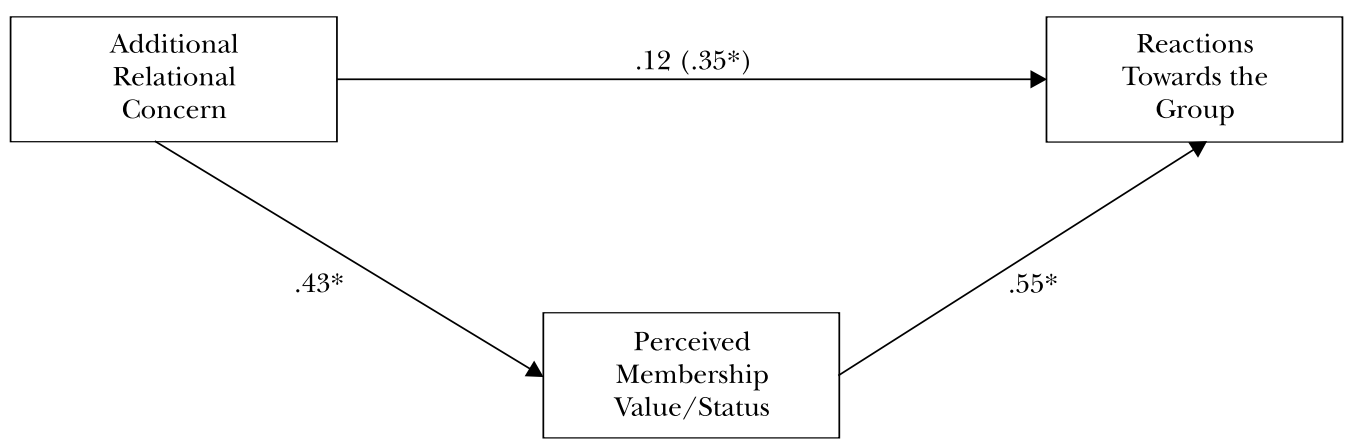

Figure 1. Study 1B: Mediational analysis

Notes: Values are the standardized betas from hierarchical regression analysis. 'Perceived Membership

Value/Status' refers to combined items from Membership Value, Relative Value, and Hierarchy scales. Value in parentheses is the standardized beta for the simple association between the addition of relational concern with the combined group reaction measure, prior to the entry of the mediating variable. $\Delta R^{2}=.244, p<.001$. $* p<.05$. 
people were reacting to were not concerns about the desirability of their compensation.

The measures assessing perceived group standing and reactions towards the group also supported our hypotheses. Specifically, the resolutions that presented compensation with an effort to express the group's concern for the victim, catering to both the instrumental and relational concerns of the victim, resulted in higher levels of perceived standing and more favorable reactions towards the group. Additional analysis also suggests that the provision of relational concern in combination with compensation did not directly increase the favorability of participant reactions. The presentation of the compensation altered respondent's perceptions of membership value and status, which in turn resulted in more favorable evaluations. This supports arguments made by relational models of procedural justice (Lind \& Tyler, 1988; Tyler \& Blader, 2003; Tyler \& Lind, 1992), asserting that individuals interpret actions taken by and communications with the group as status relevant messages, and that they are what impact subsequent evaluative judgments of the group.

Participants were also more willing to accept the compensation when it was presented in tandem with an expression of relational concern. These findings suggest that there may be additional behavioral implications beyond the evaluative measures employed in this research. Not only might showing relational concern in monetary compensation result in more positive relations with the group, the resolution of the inequity itself may be further improved upon simply by taking steps to show the victim that he/she is a valued group member, possibly preventing the restitution costs from becoming even higher.

Even though the initial injustice was accidental, and therefore according to equity models only demanded equitable compensation, procedural fairness issues related to the way that compensation was delivered altered participants' perceived relationship to the group as a whole, suggesting that compensation for distributive injustices must also be procedurally just in order to ensure satisfaction with the actions taken by group decision-makers.
It is also interesting to note that the fairness of the resolution, which includes the question of whether people are receiving what they 'deserve', shows a relational effect. This suggests that the traditional equity framework, in which outcome fairness is viewed as an adequate response to unintentional harm, may be incomplete. While the favorability of outcomes is not particularly influenced by how they are delivered, their fairness is. Hence, distributive justice does appear to have a relational component. This is consistent with some earlier findings (Tyler, 1994) showing that relational criterion shaped distributive justice judgments in conflict resolution settings. This explanation, however, should be interpreted with caution. Not only was this effect not hypothesized, it was dropped in follow-up studies. Future research needs to be conducted in order to clarify the consistency of and processes explaining this finding.

\section{Study 2}

In Study 1, the compensation and the resolution letters were presented by the group in which the unintentional distributive injustice occurred even though a single group member was responsible. With procedural violations, it is difficult to restore fairness in the absence of the offender, because victims of these types of injustices often desire communication with the offender, allowing for relative status restoration such as an apology (Umbreit, 1989). However, we would expect that following an accidental distributive injustice, group representatives can compensate just as effectively as the offender. Unlike with procedural violations, unintentional inequities do not carry a specific need for interpersonal restoration between the offender and the victim. Information regarding relational concern originating from any group member during the compensation process is relevant to the recipient's evaluation of how the group values his or her membership, and will therefore serve as an antecedent to evaluations regarding the group's authority, rules, and the group itself (Tyler, 1990; Tyler \& Lind, 1992). Relationally sensitive compensatory payments should therefore result in positive reactions towards the group when the 
compensation comes from the offender or a group representative.

In Study 2, in addition to examining the source of the compensation, we also sampled participants from a different population. Instead of utilizing undergraduate participants, our sample consisted of full-time employed respondents (enrolled part-time in MBA courses). This was done to add to the generalizability of the research. The sample in Study 2 arguably has a different type of relationship to the embedded group (the university), and often have different values and beliefs than undergraduate psychology students. Replicating our findings utilizing a different sample helps preclude some of the characteristics specific to undergraduates as potential limiting factors.

\section{Method}

In Study 2, our participant pool was drawn from first-year students enrolled in the part-time MBA program at a business school in New York. All of the participants were employed full-time in organizations in New York City, were employed at their current organization for an average of 2.9 years, and attended MBA courses in the evening. The 32 participants in the study had an average age of 27 years, and exactly $50 \%$ of them were male. Because recruitment was done in a required entry-level course, participants' main area of study and current occupation varied widely. Participation was on a volunteer basis, and in exchange for their assistance, they were offered one of eight chances to win US $\$ 25$ lottery prizes.

While procedures were similar to those employed in Study 1, the complaints, resolutions, and dependent measures were adapted to reflect the perspective of an MBA student. The scenarios employed were again based in the university, because the university is a group that all participants had in common. Participants were again instructed to imagine themselves as the MBA student in each situation, and respond to questions as if they were that student.

Participants completed three cases. All three cases involved an unintentional distributive injustice that resulted in a monetary loss of approximately $\$ 250$. One complaint dealt with misinformation by a faculty member that resulted in late course enrollment fees. In a second scenario, an MBA student missed the majority of a class session because he/she had to meet a faculty member prior to that session, but the faculty member was late for the meeting, and the student felt that he/she had wasted money on a class session that he/she was not able to attend. The third complaint was regarding a monetary loss due to a mistake made by a faculty member on the grade report forms; the student's company reimbursed education costs based on grades, and was unable to process a post-term grade change for a monetary refund. Each of these scenarios was accidental, and therefore had no procedural violations inherent in the initial inequities presented. After reading each complaint, participants reviewed a written response regarding the resolution to that complaint, and were asked to complete a questionnaire regarding their justice perceptions as well as group evaluations.

Experimental manipulations and dependent measures This study employed a $2 \times 2$ mixedsubjects design, with relational concern (compensation only [settlement] or compensation with additional relational concern), as the withinsubjects factor, and source of the compensation message (group or offending party) as the between-subjects factor. Each participant received both conditions of the relational concern manipulation, and the conditions varied in the order in which they were presented as well as by the scenario with which they were matched. Participants read resolution letters sent by either the business school administration office or the offending faculty member.

Relational concern was manipulated by providing the approximate amount of $\$ 250$ monetary compensation with concern for equity alone (settlement), or with additional relational concern (expression of remorse and acknowledgement that a mistake was made). These manipulations were given in the context of a resolution letter, and were similar to those used in Study 1.

The source of the compensation message was manipulated by altering the return address and 
pronouns in the resolution letter. In the group message condition, the resolution letters were sent from a university administrator speaking as a representative of the administrative office. In the offender message condition, the faculty member who had made the mistake that resulted in the monetary loss sent the same resolution letter.

As with Study 1, a manipulation check of outcome favorability $(\alpha=.90)$ was included. The dependent measures consisted of evaluations of procedural fairness $(\alpha=.98)$, and reactions towards the group, again consisting of multiple scales assessing group evaluations, identification, and intentions to stay $(\alpha=.95)$. All measures were similar to those in Study 1, altered only to address the MBA program as the relevant group.

\section{Results}

Cell means, standard deviations, and intercell comparisons can be found in Table 2 . Analysis of outcome favorability revealed no significant main effect for relational concern $(F(1,30)=2.34, n s)$, or source of the message $(F(1,30)=0.31, n s)$. There was also no interaction found between message source and relational concern on outcome favorability $(F(1,30)=2.34, n s)$.
For the measure of procedural fairness, an analysis of variance indicated no significant effects for either source of the message $(F(1,30)=0.19$, $n s)$, or for the interaction between message source and relational concern $(F(1,30)=0.59, n s)$. However, there was a significant main effect for relational concern on procedural fairness perceptions $\left(F(1,30)=14.27, p<.001, \eta^{2}=.322\right)$. Resolution letters implying concern for the victim in addition to restoring equity resulted in higher perceptions of procedural fairness compared to when compensation alone was provided, regardless of who sent the resolution letter.

An analysis of variance conducted on reactions towards the group revealed that, as with procedural fairness, reactions to the group were not significantly effected by the source of the message $(F(1,30)=0.02, n s)$. There was also no significant interaction found between message source and relational concern on evaluations of the group $(F(1,30)=0.004, n s)$. However, a significant main effect was found for relational concern $\left(F(1,30)=12.97, p<.001, \eta^{2}=.302\right)$, such that when compensation was framed in a way that expressed concern for the victim, thereby emphasizing the victim's membership value in addition to the importance of equity, participants expressed more favorable reactions regarding the group.

Table 2. Study 2: Means and standard deviations for fairness perceptions by condition

\begin{tabular}{|c|c|c|}
\hline & $\begin{array}{l}\text { Compensation only } \\
\text { (settlement) }\end{array}$ & $\begin{array}{r}\text { Compensation \& } \\
\text { relational concern }\end{array}$ \\
\hline \multicolumn{3}{|l|}{ Outcome favorability } \\
\hline Offender message & $5.15(1.21)_{\mathrm{a}}$ & $5.15(1.65)_{\mathrm{a}}$ \\
\hline Group message & $4.90(1.39)_{\mathrm{a}}$ & $5.55(1.34)_{\mathrm{a}}$ \\
\hline \multicolumn{3}{|l|}{ Procedural fairness } \\
\hline Offender message & $3.82(1.96)_{\mathrm{a}}$ & $5.33(1.88)_{\mathrm{b}}$ \\
\hline Group message & $4.31(1.72)_{\mathrm{a}}$ & $5.31(1.51)_{\mathrm{b}}$ \\
\hline \multicolumn{3}{|c|}{ Reactions toward the group } \\
\hline Offender message & $4.65(0.98)_{\mathrm{a}}$ & $5.22(0.94)_{\mathrm{b}}$ \\
\hline Group message & $4.68(0.96)_{\mathrm{a}}$ & $5.27(0.79)_{\mathrm{b}}$ \\
\hline
\end{tabular}

Notes: Standard deviations appear in parentheses. All ratings were done on 7-point scales, and the higher the number, the higher the level of favorability, fairness, etc. 'Offender Message', $n=18$. 'Group Message', $n=14$. Means within rows that do not share subscripts differ significantly at $p<.05$ as indicated by paired $t$ test comparisons for relational concern, and LSD comparisons for message source. 


\section{Discussion}

Regardless of how the compensation was presented or who communicated the message, outcome favorability was consistently positive when equitable compensation was provided. Compensation always led to favorable feelings about the outcome, consistent with equity theory expectations. Procedural fairness perceptions and group evaluations, on the other hand, were higher when compensation was presented in a way that expressed concern for the victim compared to when that same compensation was presented without relational concern. These findings replicate those of Study 1, supporting the argument that even unintended harms raise status issues for the victim, as responding in a way that affirms status is viewed as more procedurally fair and yields more favorable evaluations. And as expected, both the offender and group representatives were able to adequately compensate the victim (not dependent on offender involvement).

\section{Study 3}

The nature of the procedural reactions of the group utilized in the previous studies raises a concern about the interpretation of the effects. Is it the communication of relational concern that drives these effects, or the communication of a lack of relational concern? We suggest that the existence of an injustice of any type (even accidental distributive injustices which have not been equated with heightened relational concern) create a need for membership reaffirmation. It is therefore not that the relational message can compound the injustice by introducing another procedural injustice (e.g. lack of concern communicated by a settlement), but that the expression of additional relational concern is necessary to maximize the favorability of subsequent reactions to the group. To further clarify this distinction, instead of examining relational concern relative to a lack of relational concern (such as a settlement), in Study 3 we examine the independent effect of concern relative to no procedural information.

Additionally, to this point we have equated the group's recognition that a mistake has been made and remorse with procedural fairness. Through this manipulation and indeed with apologetic reactions in general, the group suggests that the unjust situation was an isolated event not representative of the group's standard course of action (Schlenker, 1980). Past research has shown that these types of responses are best able to mitigate interpersonal conflict following an injustice; denials of responsibility, on the other hand, often aggravate the injustice (Bobocel \& Zdaniuk, 2005). In our manipulations, the 'no relational concern' resolution does not acknowledge that a mistake has been made, and therefore suggests a denial of the validity of the victim's concern. On the other hand, the resolution with 'additional relational concern' does pay heed to the victim's grievance, thereby acknowledging his or her rights. We argue that this additional concern for the rights of the victim is responsible for our effects. The manipulation checks have been consistent with this notion-procedural justice (and in Study 1B, perceived membership value) varies as a function of this manipulation. However, we do not view these processes as limited to mistake recognition and remorse. For this reason, in Study 3, we also attempt to replicate this effect using different types of procedural manipulations, all of which also show interpersonal concern.

\section{Method}

The participants in this study consisted of 60 undergraduate students ( $48 \%$ male) who had an average age of 25.4 years and were recruited for participation from a campus employment office posting. Unlike participants in Studies 1,2 , and 4 which were from a private North American university, participants in Study 3 were students in an Australian university. Additionally, these participants were given a cash incentive to participate instead of course credit. Although it is important to note this difference, we did not anticipate any major concerns with altering the population sampled.

As with Study 2, the complaints, resolutions, and dependent measures were adapted to reflect the university as the relevant group. Participants were again instructed to imagine themselves as the student in each situation, 
and respond to questions as if they were that student. The procedures were similar to the previous studies. Participants in the study were informed that the research investigated student opinions regarding university policies and procedures, examined one letter of complaint from a student who had filed a formal grievance against the university administration, and were again instructed to imagine themselves as the student in the situation. The grievance in this study dealt with a $\$ 200$ late registration payment fee that was incurred, even though the payment was made on time.

Experimental manipulations This study employed a four condition between-subjects design. All of the resolutions presented included $\$ 200$ compensation for the situation. However, the way that these resolutions were framed was varied experimentally. Participants in the no frame condition were simply informed that they would receive $\$ 200$ deposited to their university account. Relational concern was manipulated by three different procedural justice message frames. Three different manipulations were used in order to illustrate that the effects shown were not specific to acknowledgments of responsibility, but procedurally fair actions in general, as these actions (acknowledgment and remorse, voice, and respect) all suggest group concern for the victim. These three relational concern conditions prefaced the offer of compensation with one of the three statements:

Relational concern (acknowledgement) - 'We agree that mistakes have been made by university staff in this matter, and regret the actions taken by that staff member'.

Relational concern (voice) - 'We want you to know that the university values your opinions, and we would be happy to listen to and consider any concerns or grievances that you may have'.

Relational concern (respect) - 'We want you to know that the university respects your concerns and rights as a student and member of the university community'.

The dependent measures employed in Study 3 were identical to those of the previous studies, including a manipulation check of outcome fairness $(\alpha=.67)$, and scales measuring procedural fairness $(\alpha=.85)$ and reactions towards the group $(\alpha=.85)$.

Additional measures were collected to assist in clarifying the type of injustice participants were asked to respond to. We have suggested that the injustices presented were accidental in nature (not intentional). To test this assertion, participants were asked to assess the intent of the individual staff member and the university as a whole: 'Did the staff member [university] intend for this situation to occur?' It was also important to assess whether the staff member and university had acted negligently and were responsible for the mistake, so participants were also asked: 'Is it the staff member's [university's] job to make sure that this type of thing does not happen?', and 'Is this person [the university] responsible for your monetary loss?' These questions were all evaluated on 7-point scales, with higher numbers reflecting more intent/ negligence/responsibility. As these measures serve simply as supportive statistics, results are reported only in Table 4 and are mentioned when relevant in the general discussion.

\section{Results}

Means and standard deviations can be found in Table 3. Analysis of variance was conducted on the measure of outcome favorability, revealing that there were no significant differences between conditions on perceptions of outcome favorability $(F(3,56)=0.19, n s)$, which were consistently high $(M=6.29)$ regardless of how compensation was presented.

Analysis of variance was conducted on procedural fairness perceptions, revealing a significant effect for relational concern $(F(3,56)=4.09$, $p<.05, \eta^{2}=.180$ ), with the relational concern conditions being evaluated as more procedurally fair than the no relational concern conditions. Additional contrasts revealed that each relational concern condition was perceived as significantly more procedurally fair to subjects then when compensation was not presented with additional relational concern (see Table 3 ).

For global reactions towards the group, analysis of variance revealed a significant effect for relational concern $(F(3,56)=6.30, p<.001$, 
Table 3. Study 3: Means and standard deviations for fairness perceptions by condition

\begin{tabular}{llcc}
\hline & $\begin{array}{c}\text { Outcome } \\
\text { favorability }\end{array}$ & $\begin{array}{c}\text { Procedural } \\
\text { fairness }\end{array}$ & $\begin{array}{c}\text { Reactions toward } \\
\text { the group }\end{array}$ \\
\hline $\begin{array}{l}\text { No relational concern } \\
\text { Relational concern }\end{array}$ & $6.22(0.65)_{\mathrm{a}}$ & $5.61(0.85)_{\mathrm{a}}$ & $5.02(0.66)_{\mathrm{a}}$ \\
$\quad$ Acknowledgment and remorse & $6.33(0.59)_{\mathrm{a}}$ & $6.49(0.57)_{\mathrm{b}}$ & $5.81(0.49)_{\mathrm{b}}$ \\
$\quad$ Respectful treatment & $6.36(0.57)_{\mathrm{a}}$ & $6.24(0.62)_{\mathrm{b}}$ & $5.91(0.66)_{\mathrm{b}}$ \\
$\quad$ Voice for the offender & $6.24(0.51)_{\mathrm{a}}$ & $6.23(0.79)_{\mathrm{b}}$ & $5.41(0.68)_{\mathrm{a}}{ }_{\mathrm{b}}$ \\
\hline
\end{tabular}

Notes: Standard deviations appear in parentheses. All ratings were done on 7-point scales, and the higher the number, the higher the level of favorability, fairness, etc. $N=60$. Means within columns that do not share subscripts differ significantly at $p<.05$ as indicated by planned simple contrast comparisons. Shared subscripts with asterisks* indicates a marginally significant difference.

$\eta^{2}=0.252$ ), with subjects reporting more favorable reactions in the relational concern conditions. Additional contrasts revealed that each relational concern condition (with the exception of voice, which was marginal) yielded significantly more favorable reactions towards the group than when compensation was not presented with additional relational concern (see Table 3).

\section{Discussion}

Consistent with Studies 1 and 2, Study 3 shows that when responding to an accidental distributive injustice the provision of relational concern in addition to equitable compensation yields significantly more favorable reactions towards the group than when no relational concern is shown. This study not only replicates the previous studies, but extends these findings to other types of additional relational concern. The increase in favorable reactions towards the group following the inclusion of different types of procedural justice concern (i.e. acknowledgment of the mistake and remorse, respectful treatment, or voice for the victim) suggests that it is the message of benevolent concern underlying that procedurally fair act that is beneficial for maintaining group relations.

It is also important to note that this study examined the impact of additional relational concern relative to no information about relational concern (instead of a lack of relational concern as in Studies $1 \& 2$ ). This is an important distinction as it clarifies the need for membership reaffirmation following an injustice, and does not simply reflect an additional procedural injustice that compounds fairness concerns in the situation.

\section{Study 4}

A question does remain regarding the actual role of the relationally sensitive compensation manipulation in this study. Does the increased satisfaction with the relationally sensitive condition stem from pairing the restoration of equity with relational concern, as argued in this article, or from the status message communicated through that concern alone? In other words, is this merely an illustration of the importance of procedures, or is there something special about the distributive injustice context? We believe that when a distributive inequity has occurred, relational concern, while it may be necessary to maintain positive group-victim relations, is not in and of itself sufficient to appease an individual's desire for equity-based retribution. Therefore, under conditions of accidental distributive injustice, the value of fair procedures is not sufficient to satisfy the victim's desire for retribution in the absence of fair compensation, but it is necessary to speak to the victim's concerns regarding their group membership while also addressing the distributive inequity with appropriate compensation. We therefore would expect not simply a main effect of procedures, but an interactive pattern between the restoration of due outcomes and expressions of relational concern. 
These assertions follow a different interactive pattern than those documented by the 'fair process effect' (Brockner \& Wiesenfeld, 1996; Greenberg \& Folger, 1983), which describes favorable outcomes as yielding positive reactions even in the absence of fair processes. The typically accepted explanation for this interaction is that fair procedures are able to make up for unfavorable outcomes as those procedures justify or explain any inequity and assure the receipt of fair and favorable future outcomes (Brockner \& Wiesenfeld, 2005). This literature seems to suggest an acquisition-directed self-interest orientation where outcomes are the dominant concern. While the restoration of outcomes may be the primary concern of victims in many cases of unintentional inequity, we suggest that even when that inequity is addressed, concerns for relational status may be heightened.

Study 4 attempts to examine the independent contributions of equitable compensation and concern for the victim using an experimental design in which people either do or do not receive compensation and, separately, either do or do not receive relationally based expressions of concern from the group. Since the injustice scenarios are distributive in nature, we would expect provision of compensation to have a large effect on subsequent reactions towards the group, however we also expect that provision of compensation presented with the addition of relational concern will yield significantly more favorable reactions towards the group than compensation alone. We do not expect the result to show an additive effect, but rather an interactive effect such that procedures will not impact reactions towards the group in absence of fair equity restoration.

Hypothesis: The provision of compensation will elicit higher ratings of procedural fairness and higher reactions towards the group, but only when that compensation is presented with additional relational concern.

This assertion is counter to the equity-based expectation that victims of unintentional inequity would not be impacted by variations in procedural fairness, as long as the outcomes lost are restored. The idea that expressions of concern in the restoration process have any impact at all, especially the relatively weak and benign addition of an acknowledgment of responsibility, runs counter to these equity theory expectations.

\section{Method}

The participants in this study consisted of 65 undergraduate students (28\% male) recruited from an introductory psychology course, and had an average age of 18.9 years. This study again employed the use of scenarios concerning university-operated student housing. As in Study 1, the majority of the participants had lived in student housing ( $88 \%$ ) for an average time period of 2.6 semesters, and $98 \%$ of those with direct student housing experiences were currently living in student housing. Only one of the participants was employed by university housing, and the responses of that participant were removed from the analysis.

The procedures employed in Study 4 were similar to the previous studies. The participants in the study were informed that the research investigated student opinions regarding university policies and procedures, examined one letter of complaint from a student in university housing who had filed a formal grievance against the housing administration (identical to Study 1), and were again instructed to imagine themselves as the student in the situation.

This study employed a $2 \times 2$ between-subjects design, with compensation (no money received or receipt of US\$200) and relational concern (no concern or concern) as independent variables. Therefore, each participant in the study received only one of the four possible resolution letters manipulating compensation and relational concern.

Those participants in the no compensation condition were informed that the housing office was unable to compensate them for the situation. Those participants in the $\$ 200$ compensation condition were told in the resolution letter from the housing office that they would receive $\$ 200$ deposited to their university account. Relational concern was manipulated by the existence or lack of existence of the group's acknowledgment of the mistake in the resolution letter, similar 
to the statements employed in Studies 1 and 3. Those participants in the no relational concern condition were simply told that their complaint had been reviewed and were informed of the housing office decision regarding monetary compensation.

The dependent measures employed in Study 4 were identical to those of the previous studies, including a manipulation check of outcome favorability $(\alpha=.95)$, and scales measuring procedural fairness $(\alpha=.98)$ and reactions towards the group $(\alpha=.96)$.

\section{Results}

Results are graphically presented in Figure 2. Analysis of the manipulation check of outcome favorability revealed that there was no significant main effect for relational concern $(F(1,60)=3.54, n s)$, or an interaction between compensation and concern $(F(1,60)=0.07, n s)$, on perceptions of outcome favorability. There was, however, a significant main effect for compensation on outcome favorability $(F(1,60)=$ $\left.340.49, p<.001, \eta^{2}=.850\right)$, such that resolutions that included the equitable monetary compensation $(M=5.63)$ were seen as more favorable than those that did not include equitable compensation $(M=1.33)$.

Analysis of variance for procedural fairness yielded a significant main effect for relational concern $\left(F(1,60)=7.84, p<.01, \eta^{2}=.116\right)$, such that those participants who received a more relationally sensitive response $(M=4.18)$ perceived the resolution to be more procedurally fair than those who did not receive and a relationally sensitive response $(M=3.55)$. As with outcome favorability, a significant main effect was also apparent for compensation $(F(1,60)=331.08$, $\left.p<.001, \eta^{2}=.847\right)$, whereby participants who received equitable compensation $(M=5.89)$ judged the resolution to be more procedurally fair than those who did not receive compensation $(M=1.83)$. No significant interaction was found for procedural fairness perceptions $(F(1,60)=0.38, n s)$.

Analysis of variance was also conducted on the group reactions measure. In this study, reaction measures were analyzed while covarying for whether or not the respondent currently lived in student housing, accounting for any additional variance that may have been created by current residents' motivation to view their present situation as favorable. Consideration of resident status was important in this study because, unlike previous studies, the design was not within-subjects and therefore the effects of resident status were not consistent across conditions. A significant main effect was found for compensation $(F(1,59)=78.60, p<.001$, $\left.\eta^{2}=.571\right)$. Those participants who received

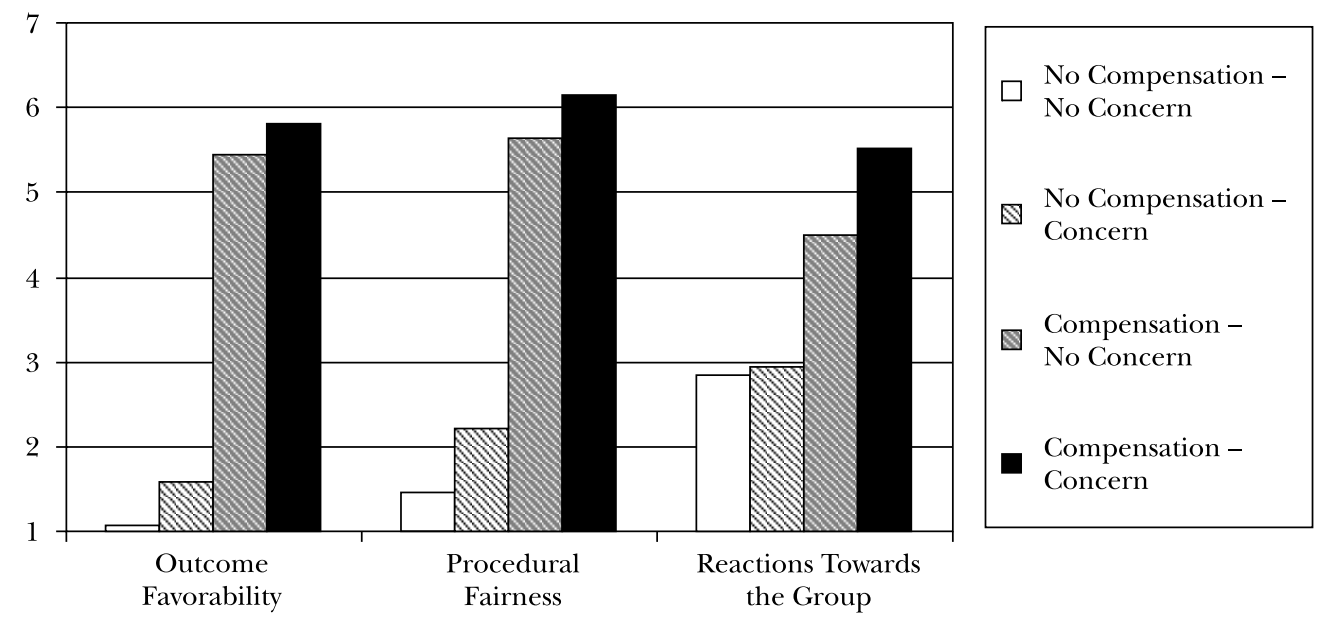

Figure 2. Study 4: Means for dependent measure scales by condition 
equitable compensation had more favorable evaluations of the overall group than those who did not receive compensation. Analyses also revealed a significant main effect for relational concern $(F(1,59)=4.90, p<.05$, $\left.\eta^{2}=.077\right)$, such that when relational concern was shown, participants judged university housing as better overall and identified more with the university housing community than when relational concern was not shown. A significant interaction was also found between concern and compensation $(F(1,59)=4.03$, $\left.p<.05, \eta^{2}=.064\right)$. Inter-cell comparisons were conducted using Tukey's HSD post hoc tests in order to further clarify the interaction effects. These comparisons revealed that there was no significant difference in evaluations of the group between the relational concern $(M=2.95)$ and no relational concern $(M=2.85)$ conditions when compensation was not provided. However when equitable compensation was provided paired with relational concern $(M=5.52)$, significantly higher evaluations were reported $(p<.01)$, compared to when compensation was not presented with additional relational concern $(M=4.49)$.

\section{Discussion}

As expected, perceptions of outcome favorability were driven by the monetary award given by the group decision-makers, regardless of whether or not that compensation was presented with relational concern. Likewise, regardless of whether or not compensation was provided, expressing responsibility and remorse for the situation increased participant perceptions of procedural fairness. Actual provision of equitable compensation for the injustice also increased perceived procedural justice reactions. This is consistent with past research arguing that failure to adequately restore justice in the appropriate way may not alleviate desires for retribution and may further diminish the victim (Vidmar, 2001, 2002). As one participant stated in their openended response indicating their reactions to a resolution letter that showed concern for the victim, but did not provide compensation, 'I felt cheated and totally uncared for. The administration seemed to have no concern for my situation'.
Both of these outcome and procedural fairness perceptions impacted subsequent evaluations of the group. When group representatives provided equitable compensation, evaluations of the group were more favorable than when equitable compensation was not provided. Presenting the resolution with relational concern did, however, further increase favorable evaluations of the group, but only when fair compensation was provided. Consistent with our hypotheses, relational concern helped to maximize the quality of group-victim relations following the equitable restoration of the accidental distributive injustice, while showing this concern alone was not sufficient to maintain a positive relationship between the victim of distributive injustice and the offending group.

As discussed earlier, this interaction pattern is unlike that described by the 'fair process effect' (Greenberg \& Folger, 1983) and documented in numerous empirical studies (Brockner \& Wiesenfeld, 1996). We agree that instrumental outcomes may still be the target of the complainant's concern in the compensation context prior to the offered resolution. However, unlike other fairness situations where fair procedures interact in order to justify or explain the inequity, in the compensation context, procedures do not necessarily relate directly to the initial injustice. Compensation procedures may provide an independent index of group/organizational concern. In addition, following from the notion that the experience of any injustice heightens sensitivity to relational concerns, victims may assign more influence to the fairness of the compensation process, even if those procedures are not directly related to the original injustice, resulting in an interaction by which the lack of concern expressed by unfair procedures diminish the beneficial impact of fair outcomes. Further research must be conducted to fully document this assertion.

\section{General discussion}

While provision of equitable compensation for accidental distributive injustices does adequately satisfy an individual's desire for outcome restoration, an equity framework 
alone is not adequate to maximize satisfaction with the resolution or to maintain positive relations between the victimized party and the group as a whole. These studies show that even in instances when the initial injustice was unintentional, the procedural justice of the resolution itself may impact subsequent reactions towards the group, even when that procedural effort is as simple as an acknowledgment of responsibility and expression of remorse. By presenting compensation in a way that shows that the group is concerned with the needs of the victim, membership status and the victim-group relationship is preserved.

These findings emphasize the need for groups and organizations to recognize the importance of procedural fairness and how status messages communicated by procedures can impact the group as a whole, even in domains where distributive fairness appears to be of primary concern, such as restoration of unintentional distributive injustices. Failure to maintain fair procedures may undermine efforts by the group to create a fair group environment in which individuals feel good about being a member. In addition, these results suggest that the impact that a procedurally fair message has on an individual's relationship with the group or organization is mediated by the perceived membership value and status that the individual member extracts from those fairness perceptions. By offering compensation in a way that reinforces the group's interpersonal commitment to the victimized member, that member may not only interpret the group's offer as a sincere expression of concern, but the victim-group relationship may also benefit as a result.

While providing participants with scenarios which they believed to be taken from actual cases appeared to be adequate to illustrate the potential impact of relational concern, it is important to investigate these findings more thoroughly. Future research in this domain should take advantage of realism created by a full laboratory experiment as well, in order to show that these effects can be replicated when participants actually experience offers of real outcomes, and has a potential impact on their own identity. Further investigations may reveal that the additional effect of small relational considerations, such as those employed in this research, are even more robust than our findings demonstrate. When considering these limitations, however, it is important to note that even third-party perceptions of procedural injustice may provoke negative reactions that still impact the group (Skarlicki, Ellard, \& Kelln, 1998; Vidmar, 2001).

These findings may also be enhanced by exploring the extent to which monetary compensation is employed, accepted, and results in behavioral implications in actual groups. The current investigation focuses on one particular type of group, namely the university, and an extension of these findings to other groups, organizational settings, and legal systems is vital to fully comprehend the intricacies of reactions to compensation. Additionally, while this study focuses on members of a group, or arguably consumers of a service provided by in-group representatives, we believe that with additional research these effects will generalize to relations with any individuals with whom a group or organization hopes to maintain positive relations, albeit employees, investors, or customers.

It may also be of interest to further examine the importance of relational concern in different types of unintentional inequities. Darley and Pittman (2003) make the distinction between non-negligent (unforeseeable) and negligent harms, whereby non-negligent harms reflect 'no fault' and demand no compensation at all, while negligent harms must be compensated for. The current investigation does not make this distinction, although by dealing with inequity situations, the idea that the victim deserves restorative outcomes is implied (Feather, 1999). In the scenarios employed, it may be assumed that university staff should not have made any errors, and therefore the university is responsible for compensation. The situations in this line of research therefore reflect some amount of negligence on the part of the university staff. These assertions are consistent with the means provided by the additional measures in Study 3 . Findings show that although the injustice was seen as unintentional, both the offending staff and the university were seen as negligent and 
should be held responsible for the injustice (see Table 4). Consistent with Darley and Pittman (2003), compensation was also shown to be a necessary component of the injustice response (Study 4). However, we show that in these types of situations, relational concern is also important. Might relational concern be important in purely non-negligent situations as well?

While the general importance of procedural fairness in group decision-making is by no means a new idea, our results go beyond the widely documented finding that unfair procedures impact reactions towards the group. Studies 3 and 4 , in particular, illustrate that our effects are not driven by unfair procedural actions, but rather by fair procedural actions. This suggests that instead of the procedural actions of group decision-makers compounding the injustice, the additional message communicated by fair procedures assuages concerns about membership elicited by the injustice. This finding that the relational messages provided by fair procedures are particularly important in the restoration of fairness, even in instances where the injustice deals exclusively with outcomes which are followed by favorable compensation, broadens our understanding of how procedural justice can impact group and organizational functioning in unexpected situations. The ability of the absence of fair procedures to undermine the compensation process is particularly interesting given the dominance of outcome favorability concerns in 'outcome by procedure interaction' patterns observed in the literature (Brockner \& Wiesenfeld, 1996), where outcomes have been shown to elicit favorable reactions even in absence of fair procedures.

Table 4. Study 3: Additional measures assessing type of injustice examined

\begin{tabular}{lcc}
\hline & Offender & Group \\
\hline Intent of the offence & $2.25(1.64)$ & $1.87(1.26)$ \\
Exhibited negligence & $6.20(1.04)$ & $6.47(0.77)$ \\
Responsible for the offence & $5.73(1.36)$ & $6.12(1.12)$ \\
\hline
\end{tabular}

Notes: Standard deviations appear in parentheses. All ratings were done on 7-point scales, and the higher the number, the higher the level of intent, negligence, etc. $N=60$.
The most important implication of this research lies in the expansion of our understanding of the processes involved in the restoration of fairness and the mitigation of retributive desires of the individual when they are responding to accidents or unintended harms. Past research has shown that intentional harms demand some type of symbolic relational message (such as punishment) in order to address the procedural aspect of the injustice implied by intent (Brown \& Harris, 1989; Tyler et al., 1997). The current research, however, suggests that this symbolic message, while it may not be necessary to address concerns with outcome favorability, may have implications for the group even when harm is unintentional. As an extension of research citing outcome restoration as necessary when distributive fairness has been unintentionally violated (Darley \& Pittman, 2003), we find that the extent to which fair procedures are employed in the restoration process can also impact reactions towards the group, above and beyond the implications of the initial injustice. Even unintended harms may heighten status concerns, and as a result, people may feel that inequities are better resolved when addressed with relational concern. Since these relational concerns are key antecedents to many important group outcomes, groups should be aware of the impact that their compensatory responses have on individual member's perceptions of the group, and that reactions towards those compensatory actions are shaped not only by the favorability of compensation, but also by the degree to which group representatives adequately respond to concerns about status.

\section{References}

Austin, W., Walster, E., \& Utne, M. (1976). Equity and the law: The effect of a harmdoer's 'suffering in the act' on liking and assigned punishment. In L. Berkowitz \& E. Walster (Eds.), Advances in experimental social psychology (Vol. 9, pp. 163-190). New York: Academic Press. Baron, R.M., \& Kenny, D.A. (1986). The moderatormediator distinction in social psychological research: Conceptual, strategic, and statistical considerations. Journal of Personality and Social Psychology, 51, 1173-1182. 
Blackman, M.C., \& Stubbs, E.C. (2001). Apologies: Genuine admissions of blameworthiness or scripted, sympathetic responses. Psychological Reports, 88, 45-50.

Bobocel, D.R., \& Zdaniuk, A. (2005). How can explanations be used to foster organizational justice? In J. Greenberg \& J. A. Colquitt (Eds.), Handbook of organizational justice (pp. 469-498). Mahwah, NJ: Erlbaum.

Brickman, P. (1977). Crime and punishment in sports and society. Journal of Social Issues, 33, 140-164.

Brockner, J., \& Wiesenfeld, B.M. (1996). An integrative framework for explaining reactions to decisions: Interactive effects of outcomes and procedures. Psychological Bulletin, 120, 189-208.

Brockner, J., \& Wiesenfeld, B. (2005). How, when, and why does outcome favorability interact with procedural fairness? In J. Greenberg \& J. A. Colquitt (Eds.), Handbook of organizational justice (pp. 525-554). Mahwah, NJ: Erlbaum.

Brown, B.B., \& Harris, P.B. (1989). Residential burglary victimization: Reactions to the invasion of primary territory. Journal of Environmental Psychology, 9, 119-132.

Carlsmith, K.M., Darley, J.M., \& Robinson, P.H. (2002). Why do we punish? Deterrence and just deserts as motives for punishment. Journal of Personality and Social Psychology, 83, 284-299.

Dailey, R.C., \& Kirk, D.J. (1992). Distributive and procedural justice as antecedents of job dissatisfaction and intention to turnover. Human Relations, 45, 305-317.

Darley, J.M. \& Pittman, T.S. (2003). The psychology of compensatory and retributive justice. Personality and Social Psychology Review, 7, 324-336.

Feather, N.T. (1999). Values, achievement, and justice: Studies in the psychology of deservingness. New York: Kluwer Academic/Plenum.

Gold, G., \& Weiner, B. (2000). Remorse, confession, group identity and expectancies about repeating a transgression. Basic and Applied Social Psychology, 22, 291-300.

Greenberg, J., \& Folger, R. (1983). Procedural justice, participation, and the fair process effect in groups and organizations. In P. Paulus (Ed.), Basic group processes (pp. 235-256). New York, Springer-Verlag.

Heider, F. (1958). The psychology of interpersonal relations. New York: Wiley.

Hogan, R., \& Emler, N.P. (1981). Retributive justice. In M. J. Lerner \& S. C. Lerner (Eds.),
The justice motive in social behavior. New York: Academic Press.

Horai, J. (1977). Attributional conflict. Journal of Social Issues, 33, 88-100.

Huo, Y.J., Smith, H.J., Tyler, T.R., \& Lind, E.A. (1996). Superordinate identification, subgroup identification, and justice concerns: Is separatism the problem, is assimilation the answer. Psychological Science, 7, 40-45.

Jones, D.A., \& Skarlicki, D.P. (2003). The relationship between perceptions of fairness and voluntary turnover among retail employees. Journal of Applied Social Psychology, 33, 1226-1243.

Kahan, D.M. (1996). What do alternative sanctions mean? University of Chicago Law Review, 63, 591-653.

Karp, D.R. (1998). The judicial and judicious use of shame penalties. Crime and Delinquency, 44, 277-294.

Konovsky, M.A., \& Cropanzano, R. (1991). Perceived fairness of employee drug testing as a predictor of employee attitudes and job performance. Journal of Applied Psychology, 76, 698-707.

Lind, E.A., \& Tyler, T.R. (1988). The social psychology of procedural justice. New York: Plenum.

Pepitone, A. (1975). Social psychological perspectives on crime and punishment. Journal of Social Issues, 31, 197-216.

Rumsey, M.G. (1976). Effects of defendant background and remorse on sentencing judgments. Journal of Applied Social Psychology, 6, 64-68.

Schlenker, B.R. (1980). Impression management: The self-concept, social identity, and interpersonal relations. Monterey, CA: Brooks/Cole.

Schwartz, G.S., Kane, T.R., Joseph, J.M., \& Tedeschi, J.T. (1978). The effects of post-transgression remorse on perceived aggression, attributions of intent, and level of punishment. British Journal of Social and Clinical Psychology, 17, 293-297.

Shaw, J.C., Wild, E., \& Colquitt, J.A. (2003). To justify or excuse?: A meta-analytic review of the effects of explanations. Journal of Applied Psychology, 88, 444-458.

Skarlicki, D.P., Ellard, J.H., \& Kelln, B.R.C. (1998). Third party perceptions of layoff: Procedural, derogation, and retributive aspects of justice. Journal of Applied Psychology, 83, 119-127.

Tyler, T.R. (1990). Why people obey the law: Procedural justice, legitimacy, and compliance. New Haven, CT: Yale University Press. 
Tyler, T.R., (1994). Psychological models of the justice motive. Journal of Personality and Social Psychology, 67, 850-863.

Tyler, T.R. \& Blader, S.L. (2003). The group engagement model: Procedural justice, social identity, and cooperative behavior. Personality and Social Psychology Review, 7, 349-361.

Tyler, T.R., Boeckmann, R.J., Smith, H J., \& Huo, Y.J. (1997). Social justice in a diverse society. Boulder, CO: Westview Press.

Tyler, T.R., \& Lind, E.A. (1992). A relational model of authority in groups. In M. Zanna (Ed.), Advances in experimental social psychology (Vol. 25, pp. 115-191). New York: Academic Press.

Umbreit, M.S. (1989). Crime victims seeking fairness, not revenge: Toward restorative justice. Federal Probation, 53, 52-57.

Vidmar, N. (2001). Retribution and revenge. In J. Sanders \& V. L. Hamilton (Eds.), Handbook of justice research in law. New York: Plenum.

Vidmar, N. (2002). Retributive justice: Its social context. In M. Ross \& D. T. Miller (Eds.), The justice motive in everyday life (pp. 291-317). Cambridge, UK: Cambridge University Press.

Walster, E., Walster, G.W., \& Berscheid, E. (1978) Equity: Theory and research. Boston: Allyn and Bacon.

Wood, R.E., \& Mitchell, T.R. (1981). Manager behavior in a social context: The impact of impression management on attributions and disciplinary actions. Organizational Behavior and Human Performance, 28, 356-378.

Paper received 14 September 2005; revised version accepted 13 April 2006.

\section{Biographical notes}

TYLER G. OKImoto, PhD, received his doctorate from New York University in 2005, and is currently a postdoctoral researcher at Flinders University in South Australia. His research interests are reactions to injustice and justice reparations, with particular focus on the motivations underlying the injustice experience. He also conducts research on the influence of negative expectations in organizational settings.

TOM R. TYLER, PhD, is a university professor at New York University. He teaches in the psychology department and the law school. His research explores the dynamics of authority in groups, organizations, and societies. In particular, he examines the role of judgments about the justice or injustice of group procedures in shaping legitimacy, compliance and cooperation.

\section{Appendix A}

\section{Scale items used in dependent measures}

Outcome favorability

'How favorable were the outcomes of the resolution to you?'

'How much better or worse off are your outcomes now that the issue is resolved compared to before the resolution?'

'How do your outcomes compare to what you expected when making the initial complaint?'

General fairness of the resolution (Study 1 only)

'Did you get more or less than you deserved from the resolution?'

'How fair was the resolution of this situation?'

'How fairly did housing solve this problem?'

Procedural fairness

'How fairly were you treated by the housing administration?'

'How much respect did you feel that you were treated with?'

'How much concern was shown by the housing administration for your rights?'

'How dignified was the administration's treatment of you?'

'How hard did the administration try to take into account your needs?'

\section{Reactions toward the group}

Evaluation of housing administration

'I can trust the housing office administration.'

'I respect the housing office administration.'

'I like the housing office administration.'

Overall satisfaction

'Overall, my experience in student housing was positive.'

'All in all, I am satisfied living in student housing.'

Intent to stay

'I would consider living in student housing for another year.' 
'I cannot think of another place that I would rather live.'

'I often think about leaving student housing before the year is up.' [reversed]

'I will probably look for other housing at the end of the year.' [reversed]

'I have not left student housing because I have pre-paid for the year.' [reversed]

'It would be hard for me to find housing I like as much as student housing.'

Identification with student housing

'I talk about student housing as a good place to live.'

'The values of student housing are similar to mine.'

'I am proud to tell people I live in student housing.'

'I would recommend living in student housing to a friend.'

'When someone praises student housing I feel proud.'

'Being part of student housing is a large part of who I am.'
Perceived membership value (Study $1 B$ only)

'How valued do you feel as a member of the university housing community?'

'How much do you think university housing cares about your well-being?'

'How much do you think university housing values you as a resident?'

'As a resident, how important do you think you are to university housing?'

'How much concern do you think university housing has for you as a resident?'

'How much do you think housing cares about your needs as a resident?'

Perceived value relative to staff (Study $1 B$ only)

'Compared to staff, how much are you valued as a member of housing?'

'How important do you think you are to university housing, compared to staff?'

'How much concern do you think housing has for you, compared to staff?'

'How much do you think university housing cares about your well being, compared to their concern for the well-being of university housing staff?' 